\title{
Hybrid Common Femoral Artery Surgical Revascularization Associated to Endovascular Femoropopliteal Recanalization in High-Risk (ASA 3 - 4) Patients: A Seven-Year Period Institutional Experience
}

\author{
Vlad-Adrian Alexandrescu ${ }^{1 *}$, Jean-Luc Jacquemin'2, Pierre-Arnaud Wuidar', \\ Khalid Azdad ${ }^{3}$, François Triffaux ${ }^{1}$ \\ ${ }^{1}$ Department of Vascular Surgery, Princess Paola Hospital, Marche-en-Famenne, Belgium \\ ${ }^{2}$ Department of Anesthesiology, Princess Paola Hospital, Marche-en-Famenne, Belgium \\ ${ }^{3}$ Department of Radiology, Princess Paola Hospital, Marche-en-Famenne, Belgium \\ Email: *v.alex@skynet.be
}

Received 21 November 2015; accepted 14 February 2016; published 17 February 2016

Copyright (C) 2016 by authors and Scientific Research Publishing Inc.

This work is licensed under the Creative Commons Attribution International License (CC BY).

http://creativecommons.org/licenses/by/4.0/

(c) (i) Open Access

\section{Abstract}

Objective: The present study was conceived to analyze the clinical benefit of hybrid interventions with surgical common femoral artery (CFA) reconstruction coupled to superficial femoral/popliteal endovascular recanalization for severe infrainguinal multilevel occlusive disease in high-risk ASA Class 3 - 4 patients. Material and Methods: From August 2008 until May 2015, a series of 143 hybrid infrainguinal interventions in 124 ASA Class 3 - 4 patients were performed in our department for Rutherford category 2 - 6 ischemic presentations. Patient demographics, specific risk factors, technical characteristics and patency results were retrospectively examined during a mean 36.8 months of follow-up. In a majority of $94 \mathrm{limbs}(65 \%)$, the endovascular stage of interventions focused on long $(>15 \mathrm{~cm})$ femoropopliteal occlusions in parallel to regular CFA surgical revascularization. Two or three runoff tibial trunks were evinced in $84 \%$ cases, while one or none permeable vessel was found in $23(16 \%)$ limbs. Results: Inasmuch surgical approach was successful in all cases, the endovascular stage was technically profitable in $134(93 \%)$ cases. The ABI posto-peratively improved ( $>1.5)$ in $73 \%$ of cases, while clinical presentation gained at least one Rutherford category in $89 \%$ limbs. The mean hospital stay was 6.1 days (3 - 12 days) whereas the 30-day

\footnotetext{
*Corresponding author.
} 
mortality rate in this homogeneous "high-risk" group of patients was $3.2 \%$. Global risk factors alike age $(>70$ years $/ p=0.0005)$, smoking $(p=0.0170)$ and female gender $(p=0.0111)$, together with CTOs length $(>15 \mathrm{~cm} / p=0.0470)$, severe calcifications $(p=0.0001)$, poor tibial runoff $(p=$ $0.0001)$, TASC " $C$ " and " $D$ " lesions $(p=0.360$ and $p=0.0394)$, the stent number $(n=3)$ and length $(>6 \mathrm{~cm})(p=0.0039$ and $p=0.0003)$ and the initial ABI scoring $(p=0.0051)$ showed statistical negative influence on primary patency. Conclusion: Hybrid infrainguinal revascularization may afford useful results in selected ASA "high risk" patients, owning low invasiveness, reproducibility and acceptable patency in return to punctual postoperative surveillance.

\section{Keywords}

Hybrid, Endarterectomy, Endovascular Procedures, High-Risk Patients, Subintimal Angioplasty, Lower Limb

\section{Introduction}

Concerning the Rutherford category 3 - 6 patients [1] that exhibit extended femoropopliteal atherosclerotic disease (TASC II "C-D" lesions) [2], endovascular recanalization gains proofs for encouraging clinical outcome compared to bypass [3] [4] without [5] [6], or with additional nitinol stenting [7]-[10] at short [6]-[9], equally at long-term follow-up [10] [11].

The additional hemodynamic involvement of the common femoral artery (CFA) in more complex infrainguinal occlusive presentations [2] [3] [12] was however less studied in the contemporary literature [3]. While most of these patients are either treated by femoro-popliteal bypass [2] [3] [12]-[14], or by way of CFA endarterectomy [15] [16], new reports analyzing specific endovascular recanalization techniques indicate comparable patency rates at one year [17].

It is generally accepted that current physical status of these patients represents a major concern in treatment selection and clinical outcome, whatever the type of revascularization [11]-[13] [15]-[17]. Although most of these analysis mainly focus on anatomical and technical details of revascularizations [4] [6]-[9] [16] adding or not parallel risk factor's assessment [6]-[11] [15] [16], very few focus on concomitant patient's physical status independently scored from specific co-morbidities [18].

Surgical endarterectomy for CFA atherosclerotic disease revealed to date remarkable safety and efficacy treatment standards at mid- [15] and long-term, [16] in isolated surgical [15] [16] or hybrid arterial reconstructions [19] [20].

Nevertheless, little contemporary data are available concerning hybrid revascularization for extended CFA occlusive disease that associates TASC type "C" and "D" [2] femoropopliteal chronic total occlusions (CTO), particularly in high-risk ASA 3 - 4 surgical patients [18] [20].

\section{Methods}

\subsection{Study Design and Cohort}

We performed a retrospective analysis of patients beneficiating from combined surgical CFA reconstruction coupled to endovascular SFA/popliteal revascularization (files and iconography) performed in our institution between July 2008 and April 2015. All these "hybrid" specific interventions were identified and results included in an "intention-to-treat" analysis. Fifteen patients either having previous iterative revascularizations (bypass or EVT), or featuring irregular clinical and duplex postoperative evaluation, were excluded from analysis.

This study gathers 143 ischemic limbs (Rutherford Category 2 - 6) [1] treated in 124 "high-risk" ASA Class 3 - 4 [18] patients by the same surgical and interventional team. All patients received thorough information about the type of scheduled intervention and signed informed consent. In 19 cases, staged bilateral interventions were performed. There were 78\% (97/124) men and the mean age was 76.3 (in the range 44 to 89 years). Patient characteristics, risk factors and ischemic features are summarized in Table 1 \& Table 2. Inclusion criteria assembled significant atherosclerotic CFA lesions (>70\% stenosis or occlusions) associating multilevel SFA/popliteal 
Table 1. Patient's characteristics and risk factors.

\begin{tabular}{|c|c|c|c|c|c|}
\hline $\begin{array}{l}\text { Patients characteristics } \\
\text { and risk factors }\end{array}$ & $\begin{array}{l}\text { Total limbs } \\
(\mathrm{n}=143)\end{array}$ & $\begin{array}{c}70 \% \text { or more } \\
\text { re-stenosis or } \\
\text { occlusion }(n=29)\end{array}$ & $\begin{array}{c}\text { Free of } 70 \% \\
\text { re-stenosis or } \\
\text { occlusion }(n=114)\end{array}$ & $p$ & $\begin{array}{c}\text { Relative risk } \\
\text { (95\% confidence } \\
\text { interval) }\end{array}$ \\
\hline Age $>70$ years & $\mathrm{n}=89(62 \%)$ & $\mathrm{n}=26(89 \%)$ & $\mathrm{n}=63(55 \%)$ & 0.0005 & $5.258(1.671$ - 16.55) \\
\hline Female gender & $\mathrm{n}=32(22 \%)$ & $\mathrm{n}=12(41 \%)$ & $\mathrm{n}=20(17 \%)$ & 0.0111 & $2.449(1.310-4.578)$ \\
\hline Hypertension & $\mathrm{n}=122(85 \%)$ & $\mathrm{n}=22(76 \%)$ & $\mathrm{n}=100(88 \%)$ & 0.1369 & $0.5410(0.2650-1.104)$ \\
\hline Active or $<1 / 2$ year former smoking & $\mathrm{n}=90(63 \%)$ & $n=24(82 \%)$ & $\mathrm{n}=66(58 \%)$ & 0.0170 & $2.827(1.147-6.966)$ \\
\hline Coronary Disease & $\mathrm{n}=109(76 \%)$ & $\mathrm{n}=19(65 \%)$ & $\mathrm{n}=90(79 \%)$ & 0.1462 & $0.5927(0.3057-1.149)$ \\
\hline Diabetes Mellitus & $\mathrm{n}=39(27 \%)$ & $\mathrm{n}=12(41 \%)$ & $\mathrm{n}=27(23 \%)$ & 0.0649 & $1.882(0.9916-3.573)$ \\
\hline Chronic Renal Insufficiency & $\mathrm{n}=29(20 \%)$ & $\mathrm{n}=6(20 \%)$ & $\mathrm{n}=23(20 \%)$ & 1,000 & $1.025(0.4604-2.284)$ \\
\hline End Stage Renal Disease/Dialysis & $\mathrm{n}=9(6 \%)$ & $\mathrm{n}=1(3 \%)$ & $\mathrm{n}=8(7 \%)$ & 0.6866 & $0.5317(0.0813-3.476)$ \\
\hline Hypercholesterolemia & $\mathrm{n}=130(90 \%)$ & $\mathrm{n}=25(86 \%)$ & $\mathrm{n}=105(92 \%)$ & 0.2999 & $0.6250(0.2571-1.520)$ \\
\hline Cerebrovascular disease & $\mathrm{n}=32(22 \%)$ & $\mathrm{n}=10(34 \%)$ & $\mathrm{n}=22(19 \%)$ & 0.0870 & $1.826(0.9463-3.522)$ \\
\hline COPD & $\mathrm{n}=28(19 \%)$ & $\mathrm{n}=9(31 \%)$ & $\mathrm{n}=19(16 \%)$ & 0.1135 & $1.848(0.9460$ - 3.611$)$ \\
\hline Previous contralateral revasc & $\mathrm{n}=22(15 \%)$ & $\mathrm{n}=5(17 \%)$ & $\mathrm{n}=17(15 \%)$ & 0.7754 & $1.146(0.4898-2.681)$ \\
\hline
\end{tabular}

Table 2. Clinical features of enrolled patients.

\begin{tabular}{|c|c|c|c|c|c|}
\hline $\begin{array}{c}\text { Clinical } \\
\text { characteristics }\end{array}$ & Limbs $(n=143)$ & $\begin{array}{c}70 \% \text { or more } \\
\text { re-stenosis or } \\
\text { occlusion }(n=29)\end{array}$ & $\begin{array}{c}\text { Free of } 70 \% \\
\text { re-stenosis or } \\
\text { occlusion }(n=114)\end{array}$ & $p$ & $\begin{array}{c}\text { Relative risk } \\
\text { (95\% confidence } \\
\text { interval) }\end{array}$ \\
\hline Rutherford Category 2 & $n=7(5 \%)$ & $\mathrm{n}=2(7 \%)$ & $\mathrm{n}=5(4 \%)$ & 0.6300 & $1.439(0.4252-4.871)$ \\
\hline Category 3 & $n=65(45 \%)$ & $n=12(41 \%)$ & $n=53(46 \%)$ & 0.6798 & $0.8471(0.4370-1.642)$ \\
\hline Category 4 & $n=30(21 \%)$ & $n=10(34 \%)$ & $n=20(17 \%)$ & 0.3495 & $1.462(0.7505-2.846)$ \\
\hline Category $5+6$ & $n=41(29 \%)$ & $n=16(55 \%)$ & $n=25(22 \%)$ & 0.0009 & $3.062(1.621-5.783)$ \\
\hline $\mathrm{ABI}<0.5$ & $n=51(36 \%)$ & $n=17(58 \%)$ & $n=34(30 \%)$ & 0.0051 & $2.556(1.327-4.921)$ \\
\hline ABI improvement > 1.5 & $n=104(73 \%)$ & $n=17(58 \%)$ & $n=87(76 \%)$ & 0.0649 & $0.5313(0.2798-1.008)$ \\
\hline Chr. Venuous Insufficiency & $\mathrm{n}=31(22 \%)$ & $n=10(34 \%)$ & $n=21(18 \%)$ & 0.0775 & $1.902(0.9883-3.659)$ \\
\hline Bedridden & $\mathrm{n}=24(17 \%)$ & $\mathrm{n}=8(27 \%)$ & $\mathrm{n}=16(14 \%)$ & 0.0971 & $1.889(0.9509-3.752)$ \\
\hline
\end{tabular}

occlusive disease in all cases. Exclusion criteria joined CFA or femoropopliteal aneurismal disease, post-traumatic or entrapment syndromes, previous infrainguinal PTA or stenting with secondary thrombosis, acute ischemia, Iodine contrast allergy, dementia and disagreement to follow postoperative treatment.

In a majority of $94(65 \%)$ limbs, long occlusions $(>15 \mathrm{~cm})$ were present. The number of claudicants versus CLI treated limbs was equivalent (51\% vs. 49\%, respectively).

Two or three runoff tibial trunks were evinced in $84 \%$ cases, while one or none permeable vessel were found in 23 (16\%) of limbs. Moderate-to-severe arterial calcifications [12] were present in 55 (38\%) cases (Table 3).

\subsection{Technique of Hybrid Interventions}

All patients were taking aspirin (160 mg/d) or clopidogrel $(75 \mathrm{mg} / \mathrm{d})$ at least 72 hours before the procedure.

First step common femoral artery surgical endarterectomy was performed in all cases following common procedural standards [15] [16]. Patches were routinely used for arterial reconstruction (29\% synthetic and 71\% using venous material). 
Table 3. Angiographic features.

\begin{tabular}{|c|c|c|c|c|c|}
\hline Angiographic features & $\begin{array}{l}\text { Total limbs } \\
(\mathrm{n}=143)\end{array}$ & $\begin{array}{c}70 \% \text { or more } \\
\text { re-stenosis or } \\
\text { occlusion }(n=29)\end{array}$ & $\begin{array}{c}\text { Free of } 70 \% \\
\text { re-stenosis or } \\
\text { occlusion }(n=114)\end{array}$ & $p$ & $\begin{array}{c}\text { Relative risk } \\
\text { (95\% confidence } \\
\text { interval) }\end{array}$ \\
\hline Flush SFA atscl. Disease & $\mathrm{n}=95(66 \%)$ & $\mathrm{n}=19(65 \%)$ & $\mathrm{n}=76(66 \%)$ & 1,000 & $0.960(0.4850-1.900)$ \\
\hline Profunda Femoris ostial disease & $\mathrm{n}=91(63 \%)$ & $\mathrm{n}=18(62 \%)$ & $\mathrm{n}=73(64 \%)$ & 0.8325 & $0.9351(0.4792-1.824)$ \\
\hline Long CTO [18] > $15 \mathrm{~cm}$ & $\mathrm{n}=94(65 \%)$ & $\mathrm{n}=24(82 \%)$ & $\mathrm{n}=70(61 \%)$ & 0.0470 & $2.502(1.018-6.152)$ \\
\hline Intermediate CTO [18] 5 - $15 \mathrm{~cm}$ & $\mathrm{n}=39(27 \%)$ & $\mathrm{n}=8(27 \%)$ & $\mathrm{n}=31(27 \%)$ & 1,000 & $1.016(0.4912-2.101)$ \\
\hline Focal Calcifications [18] & $\mathrm{n}=88(62 \%)$ & $\mathrm{n}=18(62 \%)$ & $\mathrm{n}=70(61 \%)$ & 1,000 & $1.023(0.5232-1.999)$ \\
\hline Mild+Moderate Calcifications [18] & $\mathrm{n}=37(26 \%)$ & $\mathrm{n}=8(27 \%)$ & $\mathrm{n}=29(25 \%)$ & 0.8152 & $1.091(0.5294-2.250)$ \\
\hline Severe Calcifications [18] & $\mathrm{n}=18(12 \%)$ & $\mathrm{n}=14(48 \%)$ & $\mathrm{n}=4(4 \%)$ & 0.0001 & $6.481(3.795-11.07)$ \\
\hline Tibial runoff: 3 & $\mathrm{n}=50(35 \%)$ & $\mathrm{n}=9(31 \%)$ & $\mathrm{n}=41(36 \%)$ & 0.6690 & $0.8370(0.4124-1.699)$ \\
\hline runoff: 2 & $\mathrm{n}=70(49 \%)$ & $\mathrm{n}=10(34 \%)$ & $\mathrm{n}=60(53 \%)$ & 0.0977 & $0.5489(0.2747-1.097)$ \\
\hline runoff: 1 & $\mathrm{n}=21(14 \%)$ & $\mathrm{n}=16(55 \%)$ & $\mathrm{n}=5(4 \%)$ & 0.0001 & $7.150(4.056-12.60)$ \\
\hline runoff: 0 & $n=2(2 \%)$ & $\mathrm{n}=2(7 \%)$ & $\mathrm{n}=0$ & 0.0400 & $5.222(3.720-7.331)$ \\
\hline Main CTO Segment: SFA Proximal & $\mathrm{n}=19(13 \%)$ & $\mathrm{n}=5(17 \%)$ & $\mathrm{n}=14(12 \%)$ & 0.5407 & $1.360(0.5905-3.131)$ \\
\hline SFA Mid & $\mathrm{n}=42(29 \%)$ & $\mathrm{n}=10(34 \%)$ & $\mathrm{n}=32(28 \%)$ & 0.5010 & $1.266(0.6437$ - 2.488) \\
\hline SFA + Popliteal extension & $\mathrm{n}=57(40 \%)$ & $\mathrm{n}=19(65 \%)$ & $\mathrm{n}=38(33 \%)$ & 0.0826 & $2.867(1.440-5.709)$ \\
\hline Popliteal Segm. 1 (P1) & $\mathrm{n}=8(6 \%)$ & $\mathrm{n}=3(10 \%)$ & $\mathrm{n}=5(4 \%)$ & 0.2045 & $1.947(0.7461-5.081)$ \\
\hline Popliteal Segm. 2 (P2) & $\mathrm{n}=12(8 \%)$ & $\mathrm{n}=4(14 \%)$ & $\mathrm{n}=8(7 \%)$ & 0.2633 & $1.966(0.6355$ - 6.079) \\
\hline Popliteal Segm. 3 (P3) & $\mathrm{n}=5(4 \%)$ & $\mathrm{n}=2(7 \%)$ & $\mathrm{n}=3(2 \%)$ & 0.2670 & $2.621(0.4588-14.97)$ \\
\hline TASC II: “B” lesions & $\mathrm{n}=25(17 \%)$ & $\mathrm{n}=9(31 \%)$ & $\mathrm{n}=16(14 \%)$ & 0.0517 & $2.124(1.100-4.101)$ \\
\hline TASC II: “C” lesions & $\mathrm{n}=77(54 \%)$ & $\mathrm{n}=21(72 \%)$ & $\mathrm{n}=56(49 \%)$ & 0.0360 & $2.250(1.068-4.740)$ \\
\hline TASC II: “D” lesions & $\mathrm{n}=41(29 \%)$ & $\mathrm{n}=13(44 \%)$ & $\mathrm{n}=28(24 \%)$ & 0.0394 & $2.021(1.070-3.818)$ \\
\hline
\end{tabular}

Primary infrapopliteal endovascular recanalization (endoluminal or subintimal) was performed in each patient in SFA and/or popliteal segments, owing direct arterial punctures after surgical stage completion. Patients currently received 3500 - $5000 \mathrm{IU}$ heparin administrated before CFA clamping, that were not reversed at the end of the procedure. All femoropopliteal recanalizations were initiated by crossing the "less-resistance" (commonly extra-luminal) CTO plane, using curved 0.035-inch. hydrophilic guidewire passages. Subintimal procedures were carried out following previously reported protocols [5] [6]. Downstream re-entry into the native arterial lumen was confirmed by brief contrast injections in every extra-luminal revascularization. In 10 (7\%) cases, cutting balloons were used to negotiate dense calcifications in the adductor's tunnel. Selective self-expanding nitinol stents (various manufacturers) were specifically employed if $>30 \%$ residual stenosis, or since femoropopliteal irregular "coralliform" calcifications or wall "elastic-recoil" was present. The length of stents was adapted upon each atherosclerotic presentation favoring the less extended implants whenever feasible. Complementary details of endovascular procedures are depicted in Table 4. All patients continued lifelong aspirin therapy $(160 \mathrm{mg} / \mathrm{d})$, which was accompanied by clopidogrel for 3 months after the procedure.

\subsection{Definitions}

The Rutherford clinical stratification [1] was used to define different initial ischemic presentations, while the TASC II classification [2] for femoropopliteal atherosclerotic disease severity was employed to define specific categories of infra-inguinal lesions (Table 3). All included patients were subjects for systematic preoperative multidisciplinary evaluation, including surgical and anesthetic assessment. They all exhibit equivalent ASA 
Table 4. Particularities of hybrid procedures.

\begin{tabular}{|c|c|c|c|c|c|}
\hline Endovascular Technique & $\begin{array}{l}\text { Total Limbs } \\
(\mathrm{n}=143)\end{array}$ & $\begin{array}{c}70 \% \text { or more } \\
\text { re-stenosis or } \\
\text { occlusion }(n=29)\end{array}$ & $\begin{array}{c}\text { Free of } 70 \% \\
\text { re-stenosis or } \\
\text { occlusion }(n=114)\end{array}$ & $p$ & $\begin{array}{c}\text { Relative Risk } \\
\text { (95\% confidence } \\
\text { interval) }\end{array}$ \\
\hline Total PTA without stenting & $\mathrm{n}=19(13 \%)$ & $\mathrm{n}=7(24 \%)$ & $\mathrm{n}=12(11 \%)$ & 0.0677 & $2.077(1.031-4.183)$ \\
\hline PTA/SFA & $\mathrm{n}=5(4 \%)$ & $\mathrm{n}=2(7 \%)$ & $\mathrm{n}=3(3 \%)$ & 0.2670 & $2.044(0.6632-6.303)$ \\
\hline PTA/Popliteal & $\mathrm{n}=14(10 \%)$ & $\mathrm{n}=8(27 \%)$ & $\mathrm{n}=6(5 \%)$ & 0.0815 & $3.510(1.928-6.391)$ \\
\hline 1 Stent & $\mathrm{n}=67(47 \%)$ & $\mathrm{n}=14(48 \%)$ & $\mathrm{n}=53(46 \%)$ & 1,000 & $1.059(0.5526-2.028)$ \\
\hline 2 Stents & $\mathrm{n}=50(35 \%)$ & $\mathrm{n}=11(37 \%)$ & $\mathrm{n}=39(34 \%)$ & 0.8277 & $1.137(0.5835-2.214)$ \\
\hline 3 Stents & $\mathrm{n}=7(5 \%)$ & $\mathrm{n}=5(17 \%)$ & $\mathrm{n}=14(12 \%)$ & 0.0039 & $4.048(2.237-7.323)$ \\
\hline Stents length $>6 \mathrm{~cm}$ & $\mathrm{n}=38(27 \%)$ & $\mathrm{n}=16(55 \%)$ & $\mathrm{n}=22(19 \%)$ & 0.0003 & $3.401(1.810-6.392)$ \\
\hline Associated BTK Angioplasties & $\mathrm{n}=28(19 \%)$ & $\mathrm{n}=9(31 \%)$ & $\mathrm{n}=19(16 \%)$ & 0.1135 & $1.848(0.9460-3.611)$ \\
\hline $\begin{array}{l}\text { Associated Ostial SFA + PF } \\
\text { endarterectomies }\end{array}$ & $\mathrm{n}=124(86 \%)$ & $\mathrm{n}=23(79 \%)$ & $\mathrm{n}=101(88 \%)$ & 0.2208 & 0.5874 \\
\hline
\end{tabular}

grade 3 or 4 [18] physical status on regular anesthesiology evaluation and were uniformly stratified as "high-risk" candidates for bare surgical in- and outflow concomitant interventions. The procedural success was defined as femoro-tibial straight arterial flow passage without $30 \%$ or more residual stenosis, distal embolism, intimal flaps, or "in situ" thrombosis of the treated segment.

The diagnostic of PAD was sustained by clinical history and examination, ABI, Duplex and preoperative Angio-CT or Angio-MRI imaging. Primary patency represented patent reconstructed arterial axes without recurrent stenosis or need for further intervention, while primary assisted patency expressed patent revascularizations requiring equivalent angioplasty for restenosis as to maintain maximal distal perfusion. Secondary patency denoted flow restoration after transitory femoro-popliteal occlusion without need for complementary surgical gestures, while loss of patency (and follow-up cessation) was acknowledged if surgical bypass was needed to treat secondary infrainguinal arterial thrombosis.

\section{Statistical Analysis}

All results were reported in an "intention to treat" analysis. The Kaplan-Meier life-table method was employed as to determine outcome of primary, assisted primary patency, secondary patency and the limb salvage rates. These parameters were examined and stratified as markers of follow-up for all hybrid interventions. For more accuracy, specific risk factors for patency were separately analyzed at twenty-four months in the follow-up by rigorous standardization as categorical variables using the two-sided Fischer exact test (Tables 1-4). All " $p$ " value $<0.05$, were defined to have statistical significance and were noted in red in appended tables. All data were incorporated in "Graph Pad In Stat" statistics software.

\section{Results}

Patients characteristics are described in Table 1. Following the Rutherford classification [1] among all 143 treated limbs 5\% expressed Category 2, 45\% Category 3, 21\% Category 4 and 29\% Category 5 and 6 features (Table 2). Surgical CFA endarterectomy coupled to SFA/popliteal endovascular recanalizations were performed in all cases during the same interventions. This cohort of patients gathered 25 (17\%) TASC type "B" [2], 77 (54\%) type "C" and 41 (29\%) type "D" infrainguinal lesions (Table 3). Among these latest type " $\mathrm{D}$ " femoro-popliteal presentations, twenty-one (15\%) associated severe CFA stenosis and twenty (14\%) complete CFA occlusions. In the whole, long $(>15 \mathrm{~cm})$ and intermediate $(5-15 \mathrm{~cm})$ CTO were present in $133(92 \%)$ of all ischemic limbs.

Long SFA occlusions extending to popliteal segments were noted in 57 (40\%) of cases. Mean CTO length treated by endovascular way was $17 \mathrm{~cm}$ (range, $2-52 \mathrm{~cm}$ ), slightly higher than similar reports in the literature [8] [10]. Single stenting was used in nearly half (47\%) of interventions while bare angioplasty sufficed in $13 \%$ of treated limbs. Two stents (35\%) or exceptionally three stents (5\%) per intervention were implanted in other 57 $(40 \%)$ of cases. In the sum, 188 stents were placed in this group of patients (3 stents in 7 limbs, 2 stents in 50 
limbs and 1 stent in 67 limbs), having $5.2 \mathrm{~cm}$ (range, 2 - $10 \mathrm{~cm}$ ) mean length (Table 4).

Associated infragenicular angioplasties (19\%) were performed either during the same intervention (12\%), or in staged approaches (7\%) following 2 - 5 days interval (ante- or retrograde accesses).

Flush atherosclerotic ostial lesions in the SFA (66\%) also in the profunda femoris (63\%) were surgically treated in comparable proportions during the initial surgical stage of interventions.

The endovascular step of all hybrid interventions was technically successful in 134 (93\%) cases. All femoropopliteal CTO recanalizations were performed by antegrade accesses in this series. Retrograde approaches were only occasionally employed to treat distal tibial occlusive disease.

Over the initially nine unsuccessful femoropopliteal recanalizations, five failed because of inability to re-enter the distal true lumen, while two others following dificulties in initiating the subintimal dissection plane. For the remnant two cases, a subsequent unsealed arterial perforation and one "elastic recoil" with collapsed extraluminal channel and early thrombosis were noted.

The mean follow-up was 36.8 months (ranging from 1 week to 68 months).

Globally in 73\% of cases ABI significantly (>1.5) improved postoperatively, while clinical presentation gained at least one Rutherford category in $89 \%$ limbs (Table 2 ).

The mean hospital stay was 6.1 days (3 - 12 days) whereas 6 cases (4.2\%) were rehospitalized during the first postoperative month (two cardiac, two respiratory, one renal and one digestive transitory dysfunctions).

The 30-day mortality rate in this homogeneous 124 "high-risk" (ASA 3 - 4) group of patients was 3.2\% (4 patients died within the first month due to: 2 myocardial infarctions, 1 respiratory collapse after bilateral pneumonia and 1 multiple organ failure after ischemic colitis). Twelve separate patients died during the follow-up (nine of them beyond 2 years after initial revascularization) and six others were lost from investigation.

During the follow-up period 33 limbs (regardless the CFA surgical treatment) presented either SFA or popliteal $>70 \%$ restenosis ( 24 cases), or straightway femoropopliteal occlusions (9 cases). There were documented 4 (2\%) stent fractures, all in $6 \mathrm{~cm}$ or longer length stents placed at the femoropopliteal junction or along the "P1” popliteal segment.

Survival rates were $93 \%, 85 \%, 66 \%, 71 \%$ and $48 \%$ at 12, 24, 36, 48 and 54 months, respectively and are further depicted in Figure 1.

The cumulative primary patency rates $(+/-$ SEM) at same time intervals (Figure 2$)$ were: $88 \%(+/-2.9 \%), 76 \%$ $(+/-4.3 \%), 67 \%(+/-5.2 \%), 63 \%(+/-6 \%)$ and 63\% (+/-6\%), adding 97\% (+/-1.5\%), 89\% (+/-3.3\%), 84\% $(+/-4.3 \%), 80 \%(+/-5.8 \%)$ and $80 \%(+/-5.8 \%)$ assisted primary patency, while the secondary patency showed 93\% (+/-1.6\%), 86\% (+/-2.5\%), 79\% (+/-3.4\%), 77\% (+/-3.7\%) and 77\% (+/-3.7\%), respectively values. Limb salvage proportions (+/-SEM) at identical periods were: $96 \%(+/-1.2 \%), 91 \%(+/-2.1 \%), 88 \%(+/-2.6 \%)$, $86 \%(+/-3.1 \%)$ and $86 \%$, consequently (Figure 2$)$.

We noted nine (6.3\%) major postoperative complications (2 instable angina, 2 acute renal insufficiencies implying temporary dialysis, 1 uncontrolled foot sepsis necessitating amputation, 2 complete early thrombosis requiring urgent bypass, 1 severe bilateral pneumonia and 1 ischemic colitis). There were equally 16 (11\%) minor complications (2 transitory perforations, 1 distal arterial spasm, 1 inguinal lymphorrhea, 3 superficial groin hematomas, 2 transient angina, 4 transient renal disturbances without external assistance requirement, 2 superficial skin infections and 1 disabling reperfusion edema).

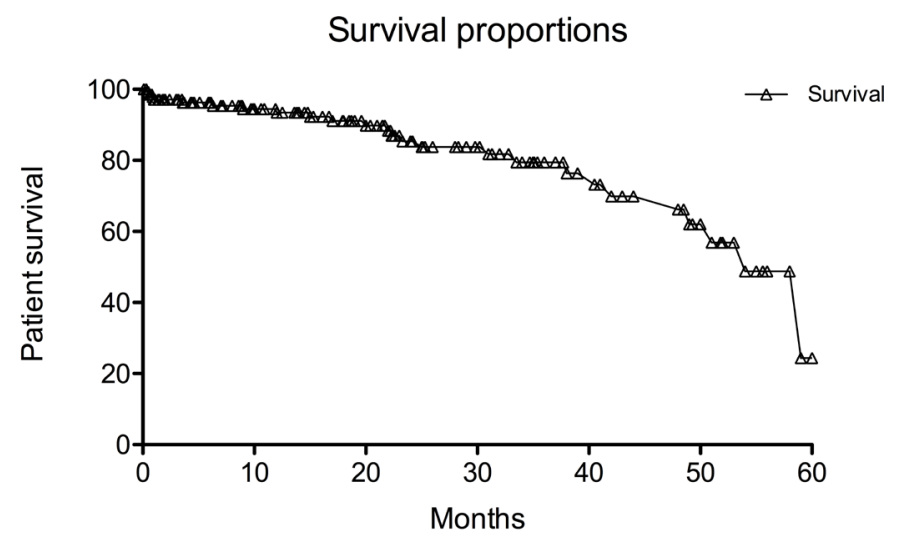

Figure 1. Survival rates. 


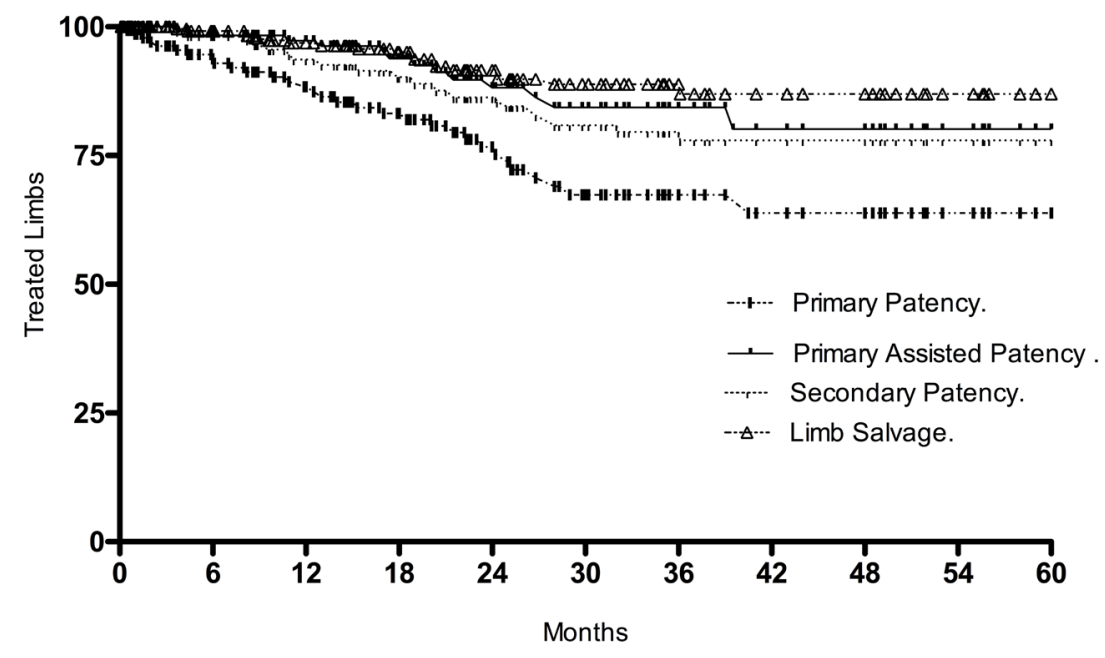

Figure 2. Primary, assisted primary, secondary patency and limb salvage rates.

The specific risk factors for primary patency were independently analyzed as categorical variables at 2 years (maximal homogeneity of subgroups), applying the two-sided Fischer exact test (Tables 1-4).

While age ( $>70$ years $/ p=0.0005$, RR: 5.2 , CI: $1.67-16.5$ ), smoking ( $p=0.0170$, RR: 2.8 , CI: $1.14-6.96)$ and female gender ( $p=0.0111$, RR: 2.4, CI: 1.31 - 4.58) were global negative predictors in this population characteristics (Table 1), angiographic features such as the CTOs length $(>15 \mathrm{~cm} / p=0.0470$, RR: 2.5, CI: 1.01 6.15 ), the presence of severe calcifications ( $p=0.0001$, RR: 6.4, CI: 3.79 - 11.07) and single or none tibial vessel runoff ( $p=0.0001$, RR: 7.1, CI: $4.05-12.6$ and $p=0.0400$, RR: 5.2, CI: $3.72-7.33)$ also showed statistical significance in primary patency values (Table 3 ).

Among additional risk determinants, the TASC "C" and "D" lesions ( $p=0.360, \mathrm{RR}: 2.2, \mathrm{CI}: 1.10-4.10$ and $p$ $=0.0394$, RR: 2, CI: $1.07-3.81)$, the stent number $(n=3)$ and length $(>6 \mathrm{~cm})(p=0.0039$, RR: 4, CI: 2.23 7.32 and $p=0.0003$, RR: 3.4, CI: $1.81-6.39)$, the initial ABI scoring ( $p=0.0051$, RR: 2.5, CI: $1.32-4.92)$ and the Rutherford CLI Categories $5+6$ cumulated lesions ( $p=0.0001$, RR: 4, CI: $2.19-7.40$ and $p=0.0009$, RR: 3 , CI: 1.62 - 5.78), equally revealed ponderous negative influence in postoperative femoropopliteal arterial permeability (Table 2 and Table 3).

\section{Discussion}

Previous surgical CFA endarterectomy [15] [16] and resembling subintimal femoro-popliteal recanalization [4]-[6] [10] [11] series for severe inferior limb atherosclerotic occlusive disease already revealed remarkable safety and efficacy results at mid- [5] [15] and long-term [10] [11] [16]. Parallel contemporary studies also emphasize encouraging primary and secondary patency results for SFA angioplasty and stenting [10] [11], even in the presence of long stenosis and occlusions [8] [10]. Additional contemporary experience that follows new advances in femoro-popliteal CTO revascularization evinces comparable results of SFA angioplasty and stenting (Figures 3-5) versus above-the-knee bypass for short and mid-term primary and secondary patency rates [22] [23].

In the same setting, novel "hybrid" surgical and endovascular revascularization strategies were also proposed in the last two decades to better adapt arterial reperfusion in multilevel atherosclerotic presentations [3] [19] [20].

Hybrid interventions appear to detain nowadays 5\% up to 21\% of current limb revascularization procedures [24], and seem to match correctly steady increasing perioperative risk in this constantly aging and pluricausal diseased cohort of patients [3] [19] [20].

The global amount of synchronous surgical and endovascular composite interventions seems to constantly rise, as recently evoked by Aho and Venermo [25] acknowledging a near to twenty fold local team progression in their daily practice throughout a similar seven-year period (from 4 in 2004, up to 73 interventions in 2011) [25].

The technical success, the short-, the long-term patency and appended limb salvage rates of hybrid interventions were documented either in retrospective [20] [26] or prospective studies [26] and seemed to afford at 


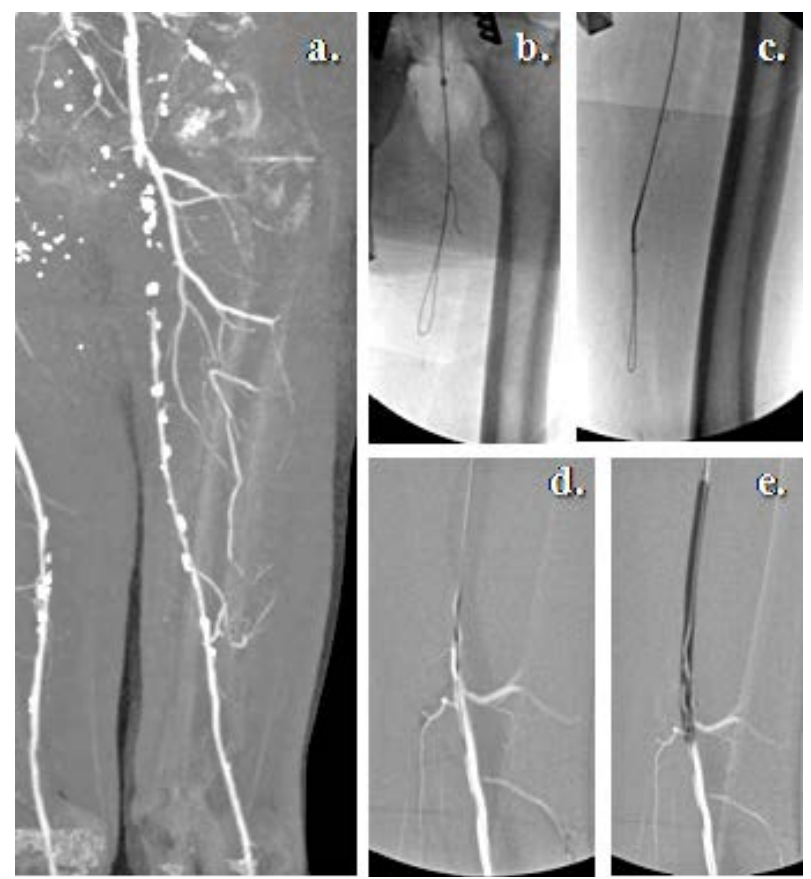

Figure 3. A first case (Rutherford 4) of hybrid infrainguinal revascularization: (a) The initial presentation on angio-CT assessment. (b) and (c) Initiation and progression of recanalization through the subintimal plane. (d) The re-entry step into the native popliteal lumen. (e) Staged angioplasties inside the extra-luminal channel.

least comparable results to the conventional endovascular and surgical revascularization procedures [19] [24]-[27].

These composite approaches consequently gather advantages and inherent limitations of both techniques [24] [25]. Among several types of hybrid interventions [20] [24], the ipsilateral common femoral endarterectomy associating distal femoropopliteal endovascular recanalization (Figures 3-5) detains a well-established role in contemporary infrainguinal procedures [20] [26] [27]. Our observation concerning 88\% and 76\% primary patency at 1 - 2 years seems to match previously available data focusing on CFA endarterectomy (96\% and 79\%) [16], and to those comparing current femoropopliteal endovascular recanalization (90\% and 78\%) [10]. Similar assisted primary patency ratio can also be revealed since comparing our 97\% and 89\% percentage with parallel $96 \%$ and $90 \%$ rates [10] reported at same time intervals. The present $96 \%$ limb salvage proportion equally accords to parallel 95\% reported values at one year [27], or by three years, our 79\% secondary patency and $88 \%$ limb salvage findings tend to match with similar $82 \%$ and correspondent $76 \%$ published rates, respectively [28].

Dusoglu et al. [20] classified hybrid interventions as simple (sHYBRID) addressing TASC type A and B lesions and complex (cHYBRID) for type C and D arterial disease. Interestingly, at a mean 30.3 months of follow-up, their $80 \%$ and $75 \%$ primary patency rates at 1 and 3 years in the sHYBRID were comparable to $87 \%$ and $81 \%$, in the cHYBRID group $(p=0.863)$. Limb salvage rates at 12 and 36 months in patients with critical limb ischemia were similar in both groups [20].

Particularly for the infrainguinal subset of hybrid procedures, our relatively inferior primary patency rates at one and two years (88\% and 76\%) compared to parallel 100\% (at one year) [25] or 93\% (at two years) [26] reported data, probably can be explained by several intrinsic factors of our study group. While the present cohort of patients assembles 83\% cumulated TASC II, type C and D severe femoropopliteal disease, other researchers include various similar subsets ranging from 40\% [25], to 48\% (cHYBRID) [20], exceptionally up to 70\% [27] equivalent challenging lesions. Seemingly, our average $17 \mathrm{~cm}$ endovascular CTO recanalization length (ranging from 2 to $52 \mathrm{~cm}$ ), gathers $65 \%$ limbs with more than $15 \mathrm{~cm}$ femoropopliteal recanalizations that slightly overpasses similar published reports [8]-[10].

It is generally accepted that extra-luminal revascularization patency as independent [3]-[5], or part of hybrid techniques [19] [24] is strongly influenced by the profile (the type of CTO) and the extent of targeted lesions 


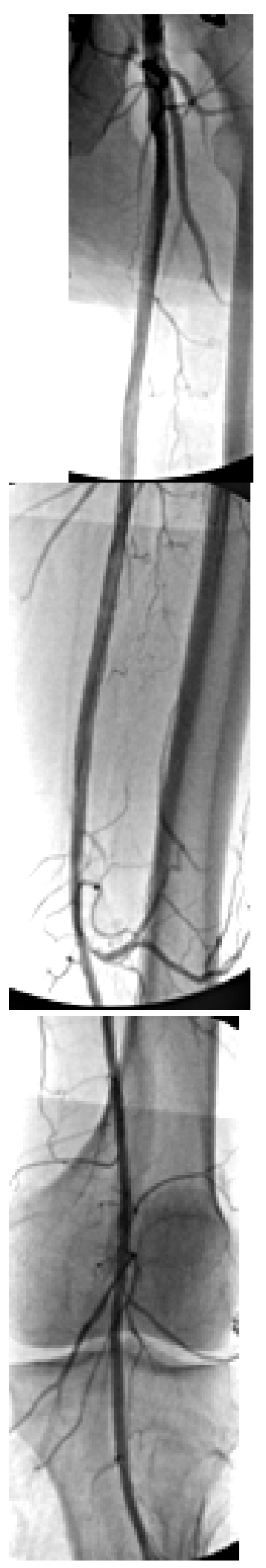

Figure 4. The completion result after CFA endarterectomy and SFA extraluminal recanalization extra-luminal recanalization, in the same case depicted in Figure 3. 


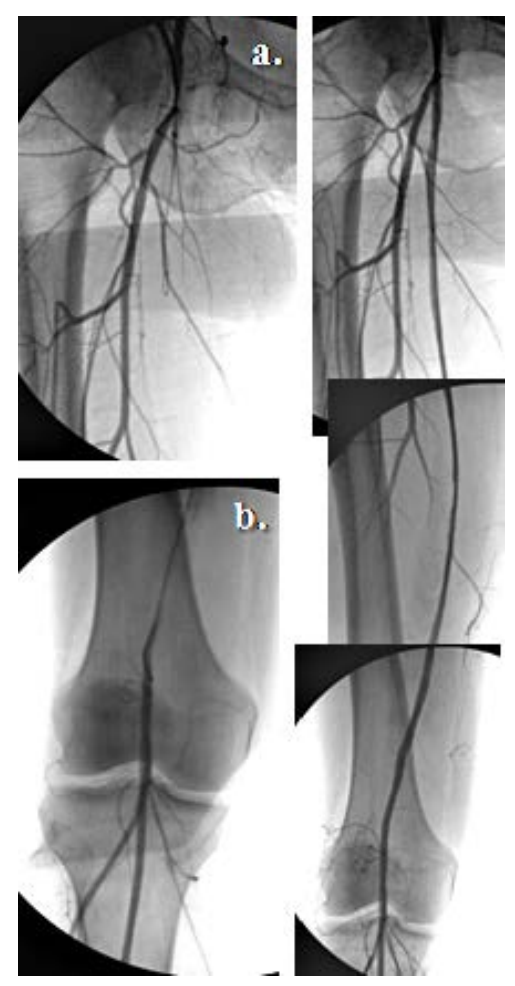

Figure 5. A second (Rutherford 5) presentation: (a) Onset of the extra-luminal SFA repermeabilization, (b) The re-entry manoeuvre into the native popliteal lumen. The appended control angiography.

(better outcome for TASC A and B lesions) [2] [12] [19] [20] [24]. This study also joins the particularity to analyze coupled CFA and femoro-popliteal type C and D treatment by combined techniques in more complex atherosclerotic presentations, albeit excluded in a majority of analogous contemporary endovascular analysis [3]-[5] [7].

The presence of moderate to severe calcifications in nearly $40 \%$ of treated limbs (Table 3 ) and the synchronous 63\% profunda femoris reperfusion combined to 66\% ostial SFA reopening cases (although rarely managed only by endovascular means in the literature) [4] [7], equally outline distinct hemodynamic features of this series compared to similar reports [3] [7] [8] [19] [20].

Previous SFA revascularization trials using self-expanding nitinol stents reported up to $32 \%$ stent fractures with consequent patency decrease from $84 \%$ to $41 \%$ at one year [8]-[10]. Our $2 \%$ stent fractures results may sustain recent clinical observation showing that nitinol stents can be implanted in the femoropopliteal arterial segment with low fracture rates at five years [3] [11].

Patency was studied according to independent hemodynamic risk factors formerly evoked in the literature [9]-[11] also matching specific features [18] of this cohort of patients (Tables 1-4).

In concordance with previous results [11], advanced age $(>70$ years $/ p=0.0005)$, smoking $(p=0.0170)$, female gender $(p=0.0111)$ and the initial ABI $(<0.5)$ scoring $(p=0.0051)$, were also found in our series as negative predictors for primary patency. Seemingly, the TASC "C" and "D" lesions $(p=0.360)$, the CTOs length $(>15 \mathrm{~cm} / p=0.0470)$ and the Rutherford CLI Categories 5 and 6 clinical presentations $(p=0.0001)$, equally appeared to hamper the postoperative hemodynamic results and corroborate with parallel published observation [19] [28].

Conversely, different from similar analysis [28] the presence of diabetes $(p=0.0640)$ and renal insufficiency ( $p=0.686)$ as individual morbid entities did not reveal significant influence for patency in this group of study. However, the independent presence of severe calcifications $(p=0.0001)$ and the poor distal run-off represented by one or none tibial vessel $(p=0.0001)$, genuinely revealed statistical significance in primary patency. Particularly for this contingent of patients, the number of stents $(n=3 / p=0.0039)$ and their length $(>6 \mathrm{~cm} / p=0.0003)$ also proved negative influence on arterial permeability. 
Our mean length of hospital stay (6.1 days) was shorter than similar bypass reports [20]-[22] [27], yet slightly longer than analogous uncombined endovascular series (acknowledging accepted limits for technical feasibility) [9]-[11]. Otherwise, this observation harmonizes with parallel hybrid series results [20] [27].

The present analysis gathers 9 (6.2\%) major and 16 (11\%) minor postoperative complications in a whole $3.2 \%$ of 30-day mortality rate. Inasmuch contemporary literature discloses up to $19 \%$ mortality and $61 \%$ morbidity for simultaneous inflow and outflow bypasses [24], hybrid interventions seem to enable concomitant multiple arterial axes reconstruction with lower $11 \%$ morbidity and associated $1.4 \%$ mortality reported proportions [24].

The marginally higher mobi-mortality documented in this analysis can be explained by the homogeneous propensity of frail ASA 3 - 4 patients intentionally included for this strategy for treatment. At our best knowledge, this series holds some distinct features engendered by its uniform density of high-risk surgical patients, by reproducible anatomical location for infrainguinal atherosclerotic disease and by its constant in- and outflow surgical and endovascular techniques owing unvarying recanalization protocols in all cases. Although patency uncertainty around endovascular femoropopliteal recanalization still exists [4] [7] [12], we shear the belief that the present hybrid technique avails low invasiveness and adequate feasibility benefits [10] [24] [27] [28] in growing number of ASA 3 - 4 fragile patients. This aging contingent featuring multilevel atherosclerotic occlusive disease may effectively be of advantage for receiving less aggressive and adapted revascularization strategy to their frail clinical condition.

\section{Limitations}

Undoubtedly, the present investigation bears inherent limitations primary inflicted by its retrospective profile and by the restricted number of joined cases. Our risk factors analysis equally encountered statistic limitations shaped by the small subpopulations profile disabling more extensive multivariable analysis. The gathering of different arterial occlusive backgrounds (bare atherosclerotic, diabetic or renal presentations) and the association of various manufacturing self-expanding nitinol stents may also a be source for indeterminations in thorough restenosis risk appraisal. Additionally, patency results do not include some new endovascular technologies, alike drug eluted devices and retrograde calf or popliteal accesses for recanalization with controlled utilization only in our recent clinical experience. Finally, the present study was not structured as a comparison between hybrid against other revascularization methods because the majority of these ASA 3 - 4 patients had no homologous risk group for more aggressive therapy (anesthetic contra-indication, lack of venous conduit, etc.) [12]-[15], to be weighted.

\section{Conclusion}

Hybrid infrainguinal revascularization may afford beneficial treatment options, particularly for high-risk comorbidities ASA 3 - 4 patients. Meticulous patient selection and procedure's main steps planning may be crucial for achieving appropriate arterial flow reconstruction and limb salvage outcome.

\section{Acknowledgements}

We acknowledge all the members of our Surgery, Anesthesiology, Radiology and Intensive Care institutional departments, the "diabetic-foot group" and the medical computing teams for their unceasing input and courtesy in providing essential clinical, iconographical and statistical support to assemble this analysis.

\section{Conflict of Interest/Funding}

None.

\section{References}

[1] Rutherford, R.B., Baker, J.D., Ernst, C., et al. (1997) Recommended Standards for Reports dealing with Lower Extremity Ischemia: Revised Version. Journal of Vascular Surgery, 26, 517-538. Erratum in: Journal of Vascular Surgery, 2001, 33, 805. http://dx.doi.org/10.1016/S0741-5214(97)70045-4

[2] Norgreen, L., Hiatt, W.R., Dormandy, J.A., et al. (2007) Inter-Society Consensus for the Management of Peripheral Arterial Disease (TASC II). European Journal of Vascular and Endovascular Surgery, 33, S32-S55.

[3] Diamantopoulos, A. and Katsanos, K. (2014) Treating Femoropopliteal Disease: Established and Emerging Technolo- 
gies. Seminars in Interventional Radiology, 31, 345-352. http://dx.doi.org/10.1055/s-0034-1393971

[4] Boufi, M., Azghari, A., Belahda, K., et al. (2013) Subintimal Recanalization plus Stenting or Bypass for Management of Claudicants with Femoro-Popliteal Occlusions. European Journal of Vascular and Endovascular Surgery, 46, 347352. http://dx.doi.org/10.1016/j.ejvs.2013.06.003

[5] Bolia, A., Miles, K.A., Brennan, J., et al. (1990) Percutaneous Trans-Luminal Angioplasty of Occlusions of the Femoral and Popliteal Arteries by Subintimal Dissection. CardioVascular and Interventional Radiology, 13, 357-363. http://dx.doi.org/10.1007/BF02578675

[6] Reekers, J.A. and Bolia, A. (1998) Percutaneous Intentional Extraluminal (Sub-Intimal) Recanalization: How to Do It Yourself. European Journal of Radiology, 28, 192-198. http://dx.doi.org/10.1016/S0720-048X(98)00114-4

[7] Perrio, S., Holt, P.E., Patterson, B.O., et al. (2010) Role of Superficial Femoral Artery Stents in the Management of Arterial Occlusive Disease: Review of Current Evidence. Vascular, 18, 82-92. http://dx.doi.org/10.2310/6670.2010.00009

[8] Cheng, S.W., Ting, A.C. and Wong, J. (2001) Endovascular Stenting of Superficial Femoral Artery Stenosis and Occlusions: Results and Risk Factor Analysis. Cardiovascular Surgery, 9, 133-140. http://dx.doi.org/10.1016/S0967-2109(00)00109-5

[9] Conroy, R.M., Gordon, I.L., Tobis, J.M., et al. (2001) Angioplasty and Stent Placement in Chronic Occlusions of the Superficial Femoral Artery: Technique and Results. Journal of Vascular and Interventional Radiology, 11, 1009-1020. http://dx.doi.org/10.1016/S1051-0443(07)61331-1

[10] Ferreira, M., Lanziotti, L., Monteiro, M., et al. (2007) Superficial Femoral Artery Recanalization with Self-Expanding Nitinol Stents: Long-Term Follow-Up Results. European Journal of Vascular and Endovascular Surgery, 34, 702-708. http://dx.doi.org/10.1016/j.ejvs.2007.07.025

[11] Iida, O., Soga, Y., Hirano, K., et al. (2011) Long-Term Outcomes and Risk Stratification of Patency Following Nitinol Stenting in the Femoropopliteal Segment: Retrospective Multicenter Analysis. Journal of Endovascular Therapy, 18, 753-761. http://dx.doi.org/10.1583/11-3581.1

[12] Patel, M.R., Conte, M.S., Cutlip, D.E., et al. (2015) Evaluation and Treatment of Patients with Lower Extremity Peripheral Artery Disease. Consensus Definitions from Peripheral Academic Research Consortium (PARC). Journal of the American College of Cardiology, 65, 931-950. http://dx.doi.org/10.1016/j.jacc.2014.12.036

[13] Society for Vascular Surgery Lower Extremity Guidelines Writing Group, Conte, M.S., Pomposelli, F.B., Clair, D.G., Geraghty, P.L., McKinsey, J.F., Mills, J.L., et al. (2015) Society for Vascular Surgery Practice Guidelines for Atherosclerotic Occlusive Disease of the Lower Extremities: Management of Asymptomatic Disease and Claudication. Journal of Vascular Surgery, 61, 2S-41S. http://dx.doi.org/10.1016/j.jvs.2014.12.009

[14] Rychlik, I.J., Davey, P., Murphy, J., et al. (2014) A Meta-Analysis to Compare Dacron versus Polytetrafluorethylene Grafts for Above-Tknee Femoropopliteal Artery Bypass. Journal of Vascular Surgery, 60, 506-515. http://dx.doi.org/10.1016/j.jvs.2014.05.049

[15] Kang, J.L., Patel, V.I., Conrad, M.F., et al. (2008) Common Femoral Artery Occlusive Disease: Contemporary Results Following Surgical Endarterectomy. Journal of Vascular Surgery, 48, 872-877. http://dx.doi.org/10.1016/j.jvs.2008.05.025

[16] Ballotta, E., Gruppo, M., Mazzalai, F., et al. Common Femoral Artery Endarterectomy for Occlusive Disease: An 8Year Single-Center Prospective Study. Surgery, 147, 268-274. http://dx.doi.org/10.1016/j.surg.2009.08.004

[17] Thiney, P.O., Millon, A., Boudjelit, T., et al. (2015) Angioplasty of the Common Femoral Artery and Its Bifurcation. Annals of Vascular Surgery, 29, 960-967. http://dx.doi.org/10.1016/j.avsg.2015.02.001

[18] Fitz-Henry, J. (2011) The ASA Classification and Peri-Operative Risk. Annals of the Royal College of Surgeons of England, 93, 185-187. http://dx.doi.org/10.1308/rcsann.2011.93.3.185a

[19] Scrijver, A.M., Moll, F.L. and De Vries, J.P. (2010) Hybrid Procedures for Peripheral Obstructive Disease. Journal of Cardiovascular Surgery (Torino), 51, 833-843.

[20] Dosluoglu, H.H., Lall, P., Cherr, G.S., et al. (2010) Role of Simple and Complex Hybrid Revascularization Procedures for Symptomatic Lower Extremity Occlusive Disease. Journal of Vascular Surgery, 51, 1425-1435. http://dx.doi.org/10.1016/j.jvs.2010.01.092

[21] Aihara, H., Soga, Y., Mili, S., Okazaki, J., Yamaoka, T., Kamoi, D., et al. (2014) Comparison of Long-Term Outcome after Endovascular Therapy versus Bypass Surgery in Claudication Patients with Trans-Atlantic Inter-Society Consensus-II C and D Femoropopliteal Disease. Circulation Journal, 78, 457-464. http://dx.doi.org/10.1253/circj.CJ-13-1147

[22] Linnakoski, H., Uurto, I., Suominen, V., Vakhitov, D. and Salenius, J. (2013) Comparison of Above-the-Knee Prosthetic Femoro-Popliteal Bypass versus Percutaneous Transluminal Angioplasty and Stenting for Treatment of Occlusive Superficial Artery Disease. Scandinavian Journal of Surgery, 102, 227-233. 
http://dx.doi.org/10.1177/1457496913501591

[23] Antoniou, G.A., Chalmers, N., Georgiadis, G.S., Lazarides, M.K., Antoniou, S.A., Serracino-Inglott, F., et al. (2013) A Meta-Analysis of Endovascular versus Surgical Reconstruction of Femoropopliteal Arterial Disease. Journal of Vascular Surgery, 57, 242-253. http://dx.doi.org/10.1016/j.jvs.2012.07.038

[24] Huynh, T.T. and Bechara, C.F. (2013) Hybrid Interventions in Limb Salvage. Methodist DeBakey Cardiovascular Journal, 9, 90-94. http://dx.doi.org/10.14797/mdcj-9-2-90

[25] Aho, P.S. and Venermo, M. (2012) Hybrid Procedures as a Novel Technique in the Treatment of Critical Limb Ischemia. Scandinavian Journal of Surgery, 101, 107-113. http://dx.doi.org/10.1177/145749691210100206

[26] Joh, J.H., Joo, S.H. and Park, H.C. (2014) Simultaneous Hybrid Revascularization for Symptomatic Lower Extremity Arterial Occlusive Disease. Experimental and Therapeutic Medicine, 7, 804-810. http://dx.doi.org/10.3892/etm.2014.1513

[27] Matsagkas, M., Kouvelos, G., Arnautoglou, E., Papa, N., Labropoulos, N. and Tassiopoulos, A. (2011) Hybrid Procedures for Patients with Critical Limb Ischemia and Severe Common Femoral Artery Atherosclerosis. Annals of Vascular Surgery, 25, 1063-1069. http://dx.doi.org/10.1016/j.avsg.2011.07.010

[28] Zhou, M., Huang, D., Liu, C., Liu, Z., Zhang, M., Qiao, T. and Liu, C.J. (2014) Comparison of Hybrid Procedure and Open Surgical Revascularization for Multilevel Infrainguinal Arterial Occlusive Disease. Clinical Interventions in Aging, 22, 1595-1603. http://dx.doi.org/10.2147/CIA.S66860

\section{Abbreviations}

CLI: Critical Limb Ischemia,

CFA: Common Femoral Artery,

CTO: Chronic Total Occlusion,

SFA: Superficial Femoral Artery,

PAD: Peripheral Arterial Disease. 